\title{
A FINITE ELEMENT ANALYSIS OF WOOD IN TRANSVERSE COMPRESSION
}

A.L. Mrema, Lecturer, Department of Civil Engineering, University of Dar es Salaam, P.O. Box 35131, Dar es Salaam, Tanzania.

\section{ABSTRACT}

A two dimensional finite element analysis is utilized to predict the stress and strain distributions for wood in transverse compression. Important key variables are incorporated into the analysis to define their influence on the stress and strain distributions. These variables are geometry of loading, geometry of specimen and the orthotropic ratio of the material.

Based on the finite element analysis results, relationships are developed relating maximum stress arising from stress concentrations to the above three variables.

Possible applications of the results from this study relate to the development of more efficient design of connections such as sizing of washers for a bolted connection in wood, the sizing of reaction contact areas for beams and truss supports as well as plate sizes for railroad ties.

Uhandisi Journal Vol. 15 No. 21991 


\subsection{INTRODUCTION}

Wood and wood composites are often subjected to compression across the grain. Most research effort in wood has, however, been placed on studying the behaviour parallel to grain presumably because a large proportion of wood is principally stressed in this direction.

Designs involving perpendicular to grain behaviour of wood have been based on results obtained from such tests as the ASTM D143 method (1) which is considered very conservative (2) (3). The ASTM D143 standard test for compression requires a 2 "x2"x6" $(5 \mathrm{~cm} \times 5 \mathrm{~cm}$ $x 15 \mathrm{~cm})$ small clear specimen. Using a $2 "(5 \mathrm{~cm})$ wide metal plate, the specimen is loaded over the central third of the surface area. The test dictates that tangential loading be employed and only the stress at the proportional limit is calculated. The test does not provide information on many important influences such as geometry of loading, ring orientation, member size, rate of loading, moisture content etc. It is not known how the results of the standard test relate to in-service performance for various joint details since the actual stress and strain distributions are difficult to relate to the standard test conditions. The test method can only be used as a means of contrasting different species (4) (5). This restriction is unfortunate since a knowledge of the behaviour of wood in transverse compression is important not only in structural design but also in that segment of industry that relies on pressing wood in the transverse directions during

Uhandisi Journal Vol. 15 No. 21991 
manufacturing such as glulam, plywood and wood composite board.

In the ASTM D143 test a clearly defined ultimate load typical of most other mechanical property tests of wood is not apparent. The lack of availability of either an ultimate stress value or an allowable deformation limit for design has resulted in relying on the use of proportional limit as the basis of design. The apparent absence of an ultimate stress observation in transverse compression is, however, due to lack of a sensitive continuous recording of the stress-strain relationship (6).

Perelvgin (7) and Schniewind (8) indicate that the proportional limit stress and modulus of elasticity are different in radial and tangential directions. Moisture content and specimen height have also been found to have influence in transverse compression(9).

It has been noted that results obtained by full surface and partial plate (A.S.T.M) compression tests are very different. The partial plate compression test gives higher strength values than the full surface compression test due to the added edge effect of the former (3) (10) .

Stress distribution in transverse compression is very complex even with full surface compression. Measurements of strain in partial plate compression by Yamai (11) indicate a very complex state of strain even with simple geometric configurations.

Uhandisi Journal Vol. 15 No. 21991 


\subsection{OBJECTIVES AND SCOPE OF STUDY}

The objective of this study is to obtain a fundamental understanding of the behaviour of wood and wood composites in transverse compression. The solution describing this behaviour should be simple to use and of practical value in situations commonly encountered in practice.

A fundamental solution is desired for several reasons. Firstly, it is known that the behavior of wood or a wood composite is influenced by many factors such as species, moisture content, ring orientation, geometry of loading, rate of loading, temperature etc. Some of these influences are not fully known. A solution which would take into account all possible influences is difficult to achieve. Secondly, from a practical point of view, even if such a solution could be achieved, it would involve too many unknown parameters which would have to be determined for every particular practical situation.

It can be recognized, however, that some of the most important influencing factors can be taken into account if one can characterize some fundamental properties of the problem in question. Key variables involve the relative modulus of elasticity perpendicular and in the direction of loading, the geometry of the member and that of the loading. These three variables are used as

Uhandisi Journal Vol. 15 No. $2 \quad 1991$ 
the basis for the prediction of the stress-strain behaviour of wood in transverse compression. The study is limited to plane stress conditions which are commonly encountered in compression perpendicular to grain problems.

\subsection{MODELLING TRANSVERSE COMPRESSION}

Several analytical methods could be used in the modelling of transverse compression. These methods include the finite element method, the finite difference method, beam on elastic foundation, closed form solution and contact stress of a cylinder on a flat plate. The author has reviewed all these methods and concluded that the finite element method is the most appropriate method for modelling tranverse compression (12).

\subsection{The Finite Element Model}

The elastic behaviour of wood in transverse compression is approximated as a plane stress problem. Fig. 1 illustrates the boundary conditions of a plane stress approach used for the finite element approximations.

Uhandisi Journal Vol. 15 No. 21991 


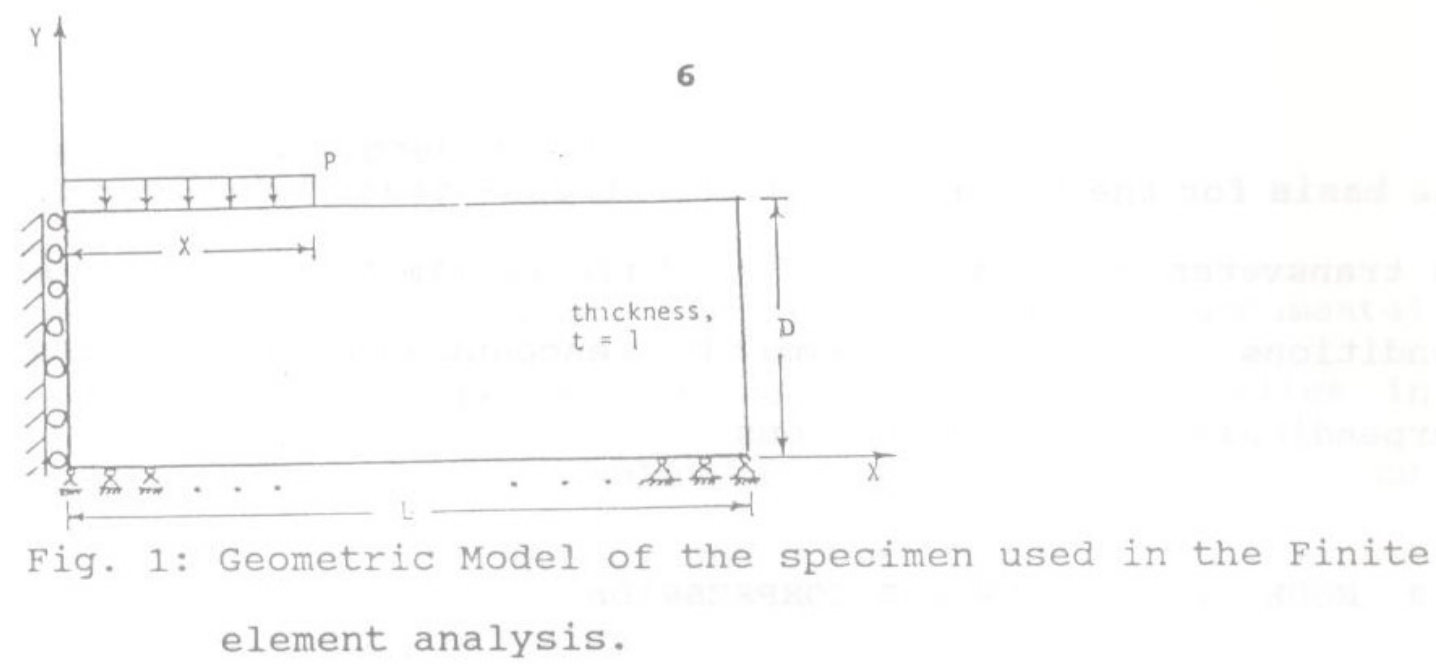

The half specimen shown in Fig. 1 was divided into small finite elements. A six node triangular element was chosen (Fig.2). Whereas a three-node element approximates a linear shape function in two dimensions, a six-node element approximates a complete second order polynomial which is a better approximation of the actual displacements.

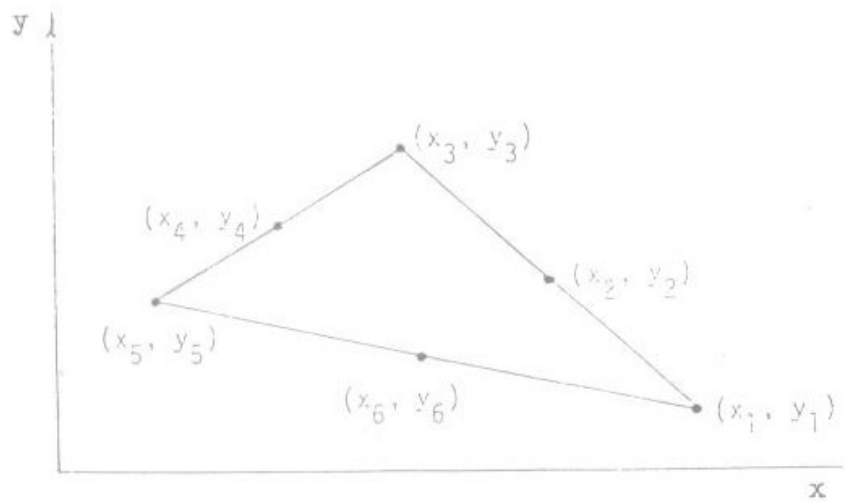

Fig.2: Six-Node triangular element

The assumptions made about the model (Fig.1) were

(a) Due to friction at the specimen interface, pin conditions exist. 
(b) Due to friction of the loading plate only vertical deformations occur at the nodes in contact with the loading plate.

(c) From symmetry of loading, all nodes at $\mathrm{x}=0$ can only deform vertically (roller conditions)

The uniform loading $\mathrm{p}$ was introduced as nodal forces.

The stress strain relationship for a linear elastic material is given in tensor notation as

$$
\sigma_{i j}=C_{i j k 1} \varepsilon_{k 1}
$$

$$
\begin{gathered}
\text { where } \varepsilon_{k l}=\text { Strain tensor } \\
\sigma_{i j}=\text { stress tensor } \\
C_{i j k 1}=\text { stiffness tensor }
\end{gathered}
$$

For an orthotropic material equation 1 simplifies (5) to

$$
\left[\begin{array}{l}
\sigma_{11} \\
\sigma_{22} \\
\sigma_{12}
\end{array}\right]=\left[\begin{array}{ccc}
C_{11} & C_{12} & 0 \\
C_{21} & C_{22} & 0 \\
0 & 0 & 2 C_{66}
\end{array}\right]\left[\begin{array}{l}
\varepsilon_{11} \\
\varepsilon_{22} \\
\varepsilon_{12}
\end{array}\right]
$$

where: 


$$
\begin{gathered}
C_{11}=\frac{E_{1} E_{2}}{E_{2}-E_{1}\left(v_{21}\right)^{2}} \\
C_{12}=C_{21}=\frac{E_{1} E_{2} v_{21}}{E_{2}-E_{1}\left(v_{21}\right)^{2}} \\
C_{22}=\frac{E_{1} E_{2}}{E_{1}-E_{2}\left(v_{12}\right)^{2}} \\
C_{66}=\mathrm{G}_{12}
\end{gathered}
$$

$\mathrm{E}_{1}, \mathrm{E}_{2}=$ Modulus of elasticity in the $\mathrm{x}$ and $\mathrm{y}$ directions respectively,

$\mathrm{G}_{12}=$ Shear modulus

$v_{21}, v_{12}=$ Poisson's ratios.

Using the stiffness matrix in equation (2) a finite element analysis was conducted in which variations in the ratio $x / L, L / D$ and the relative modulus of Elasticity (orthotropic ratio) Ey/Ex were incorporated (Fig.1).

Four interactive computer programmes were used for mesh generation, band reduction, analysis and contour plotting.

The mesh used in the analysis is shown in Fig.3. The mesh was refined close to the loading plate for more accuracy of results. The influence of mesh fineness on the results was studied by trying various mesh sizes. No significant diference in results was obtained. 


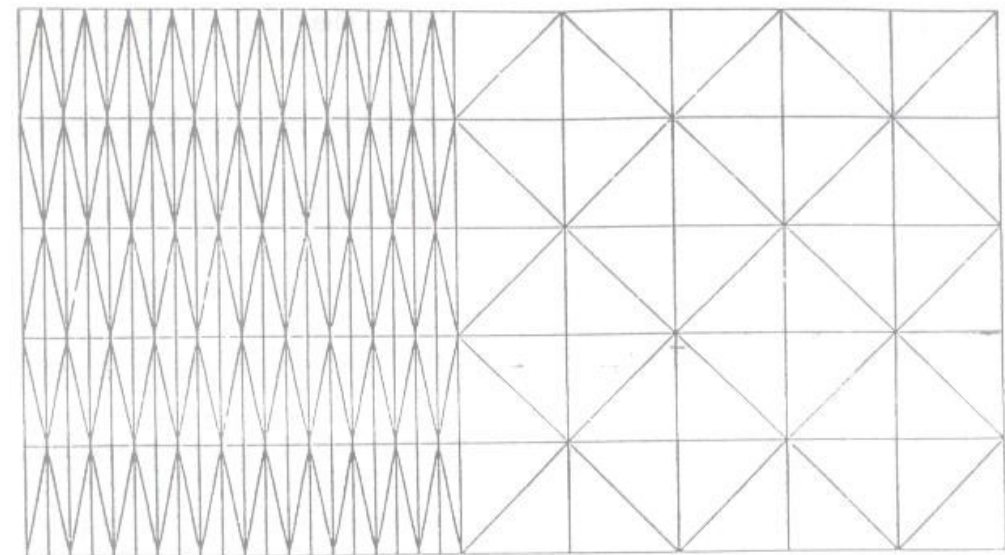

Fig.3: Mesh used in the Finite element analysis

\subsection{Results of the Finite Element Analysis}

In the analysis, an arbitrarily imposed stress of 100 units of stress was assumed along the loaded boundary. The contour plot shown in Fig. 4 is the stress distribution for this imposed stress.

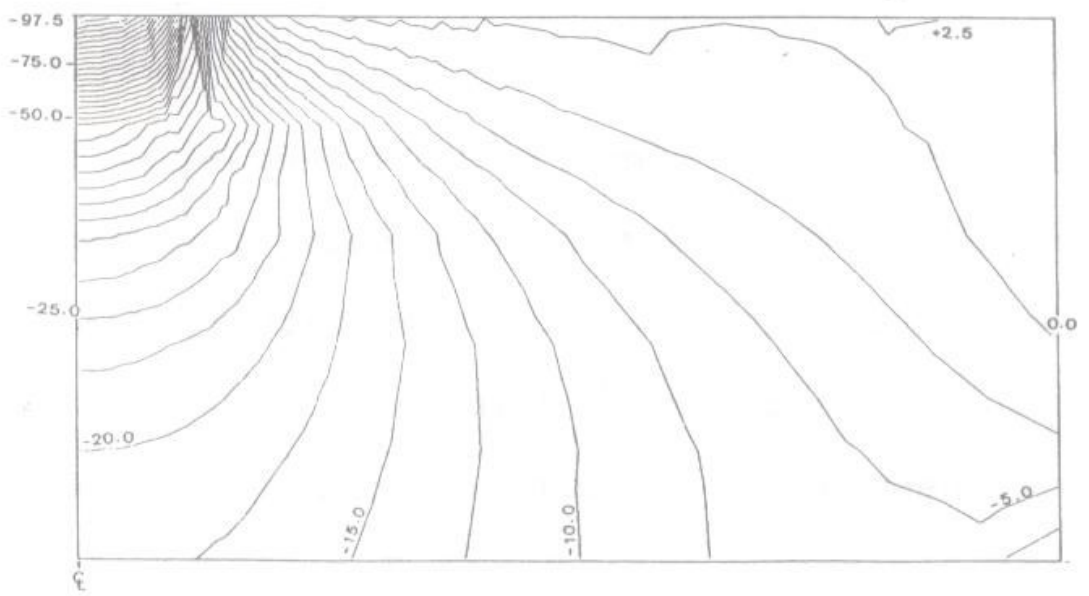

Fig.4. Vertical stress distribution as percentage of the imposed stress $(X / L=1 / 9, L / D=3.6, E y / E x=1 / 20)$ 
The vertical strain distribution within the specimen is shown in Fig. 5 at various height locations $y$.

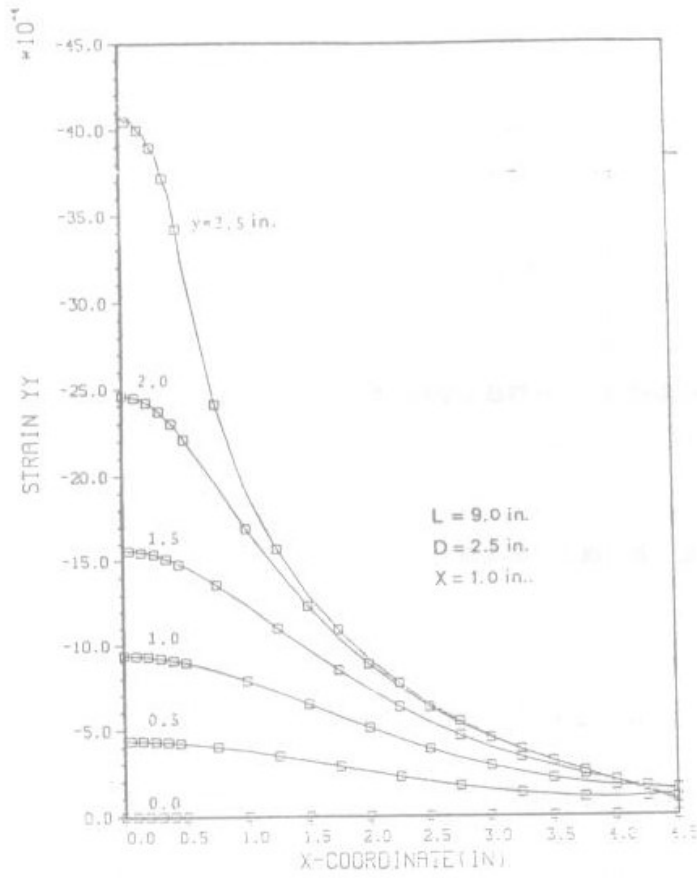

Fig.5. Vertical strain distribution $\varepsilon_{y}$, along the length

$$
(\mathrm{X} / \mathrm{L}=1 / 9, \mathrm{~L} / \mathrm{D}=3.6, \mathrm{Ey} / \mathrm{Ex}=1 / 20)
$$

A stress concentration factor was determined by using a unit external stress under the loading plate. The resulting maximum stress was defined as the stress concentration factor. Similar factors were determined for the stresses developed in the $\mathrm{x}$ axis direction. The stress concentration factors for compression in the $x$ and $y$ directions are plotted in Fig 6 and 7 respectively as functions of the ratio $\mathrm{X} / \mathrm{L}$ for various ratios of $\mathrm{L} / \mathrm{D}$ (Fig 1 ). These factors were developed for constant elastic properties (i.e. the ratio Ey/Ex was kept constant.) 
By varying the plate size to length ratio, $x / L$, it was noted that the maximum stresses developed increased with an increase in this ratio up to a value of about 0.45 . Beyond this ratio the maximum stress concentration decreased in the $\mathrm{x}$ direction (Fig.6). In the y direction, the stress concentration factor increased all the way to $\mathrm{X} / \mathrm{L}=1(\mathrm{Fig} \cdot 7)$.

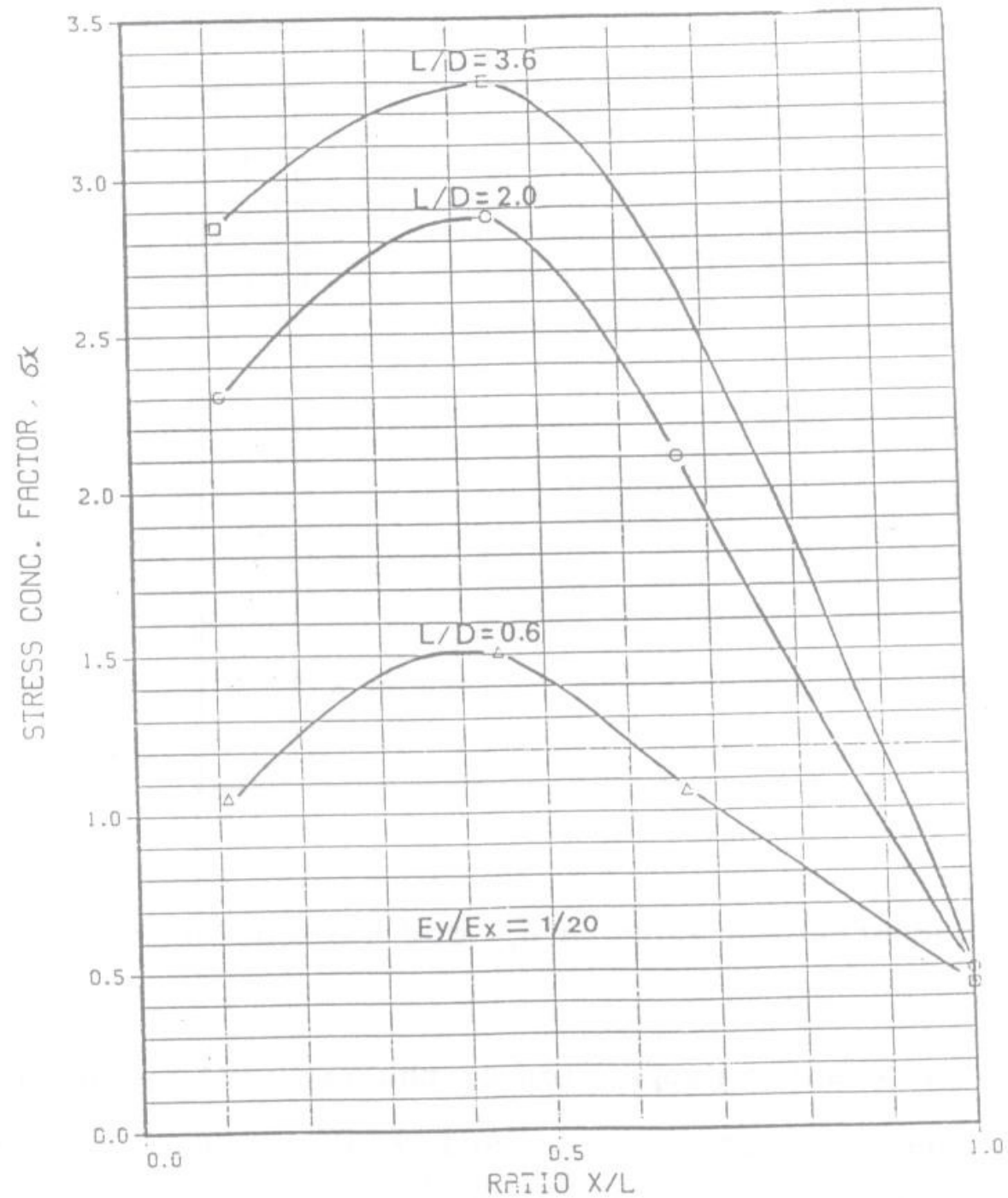

Fig.6: Stress Concentration Factors $\sigma_{\mathrm{x}}$ for Various Geometries 


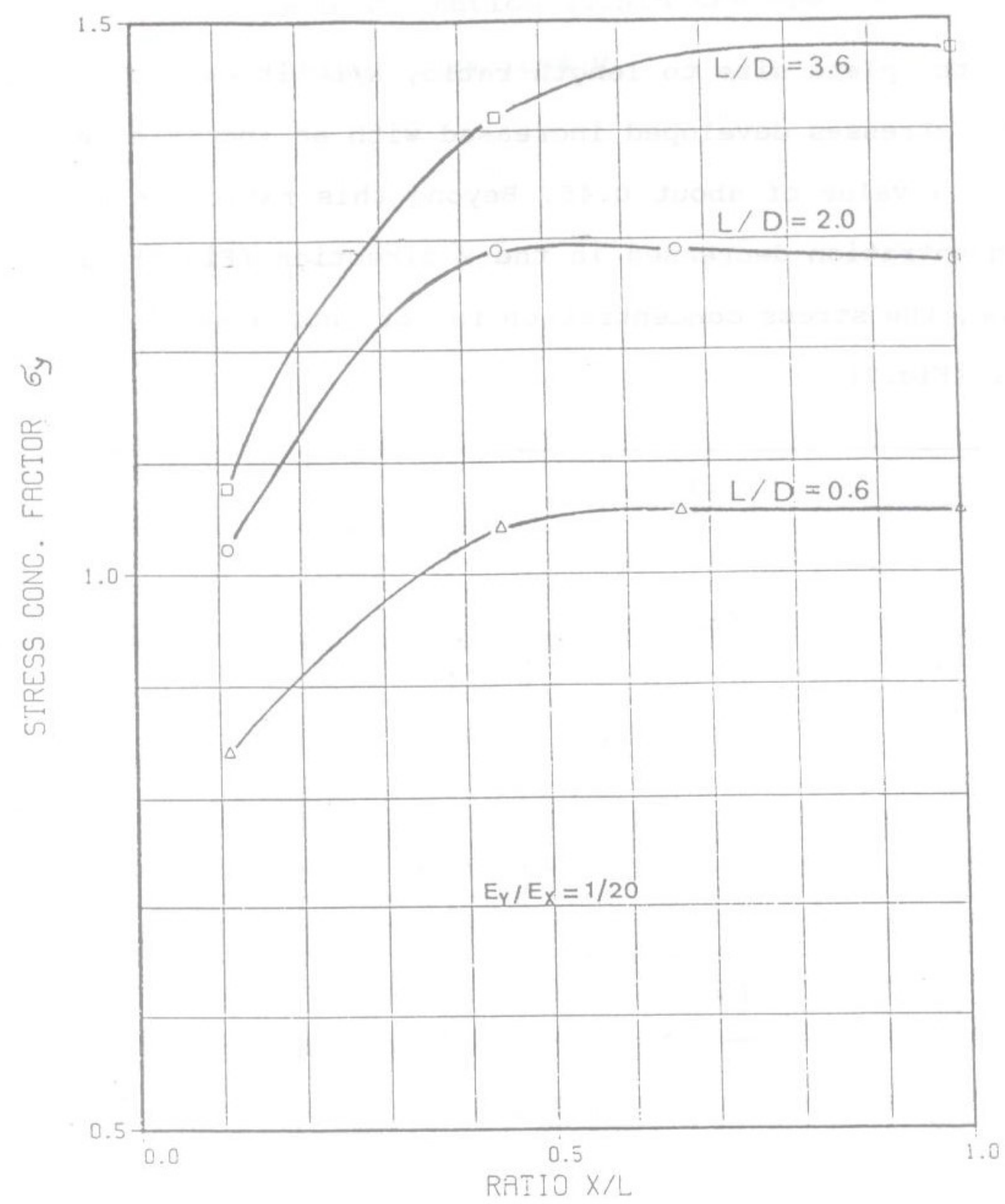

Fig. 7. Stress Concentration Factors $\sigma_{\mathrm{y}}$ for Various Geometries

The influence of the elastic properties of the material was studied by keeping the geometry of loading and that of the specimen constant while varying the ratio Ey/Ex. A plot of the maximum 
stress developed appeared to be a logarithmic function of the EY/Ex ratio. By plotting these stresses as functions of the logarithm of Ey/Ex, a straight line relationship was found for the case of compression in the y direction (Fig 8).

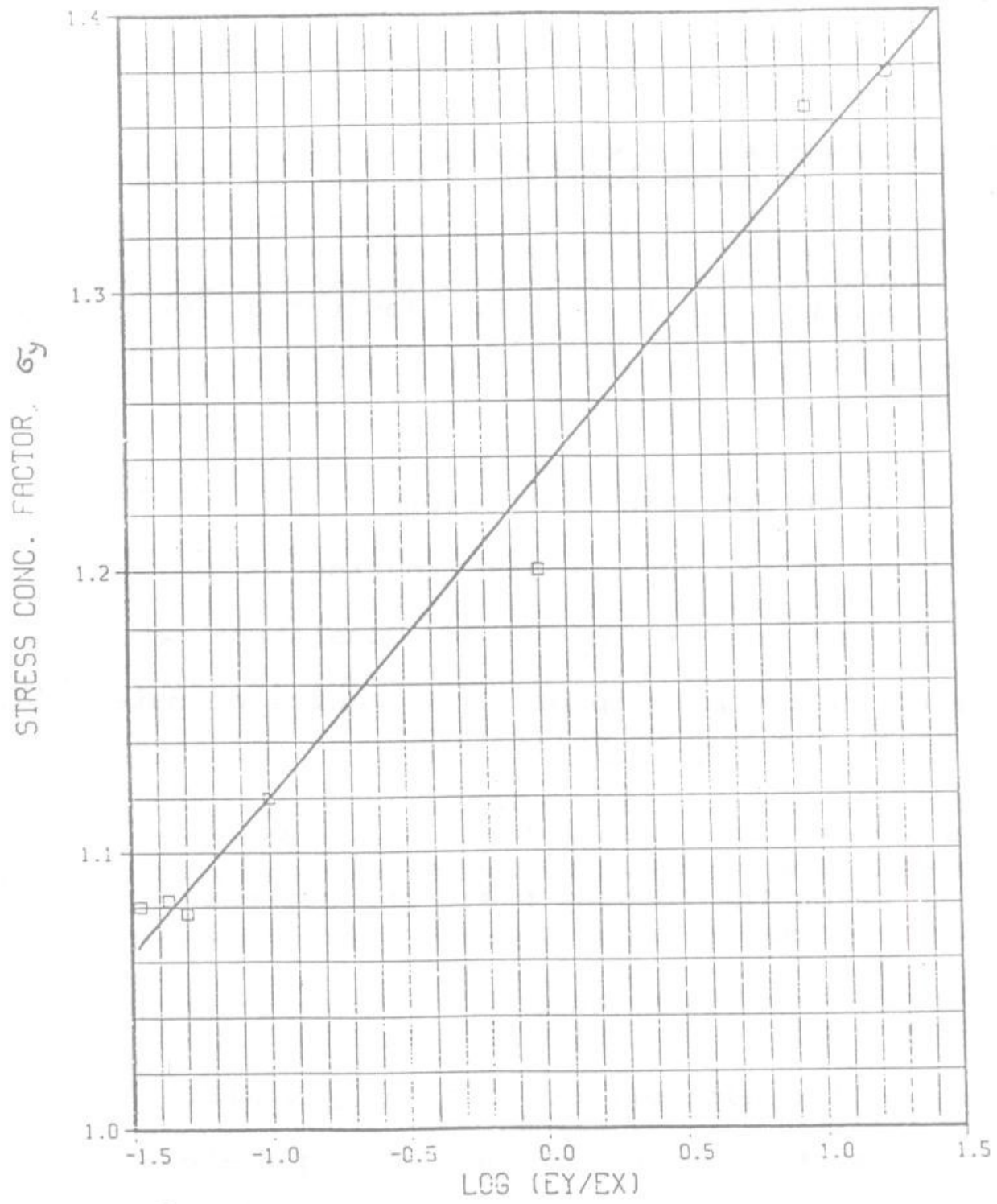

Fig. 8: Stress concentration Factors $\sigma_{y}$ as affected by the orthotropic ratio 
It is desirable to find an equation which describes the maximum stresses developed due to stress concentration in terms of the geometry of loading, the geometry of the specimen and the orthotropic ratio of the material.

A linear multiple regression model for the finite element values plotted in Figures 7 and 8 gave the regression equation.

Stress conc. Factor $=1.35+0.0993 \log ($ Ey/Ex $)$

$+0.408 \log (\mathrm{L} / \mathrm{D})+0.350 \log (\mathrm{X} / \mathrm{L})$

(Correlation coefficient, $R=0.958$ (adjusted for degrees of freedom))

\section{DISCUSSION OF RESULTS AND CONCLUSIONS}

The contour plot of the stress distribution as provided by the finite element analysis (Fig. 4) is consistent with expected behaviour based on the principles of mechanics of materials. The actual distribution is similar to the ones obtained when analyzing the stress distribution in soil below a foundation. The largest stresses occur below the loading plate and decrease with increase in depth.

The influence of the edge effect is clearly visible by observing the contours close to the edge of the loading plate. The contours indicate a very high local level of shear. This shear effect is responsible for the added load carrying capacity of the member as observed experimentally by Bodig (3). 
Contrary to expectations, the finite element analysis shows that some stresses are developed in the $\mathrm{x}$-direction even with full surface loading. This is contrary to assumptions used in simple elastic theory that no stresses exist in this direction with full surface loading.

The behaviour of wood and wood composites in transverse compression has been found to be governed by three major variables: the specimen geometry, loaded area ratio and the orthotropic ratio of the material. It is possible using Eq. 3 to predict the maximum stresses developed due to stress concentration if these three variables are known.

This study may also be useful in the development of more efficient elastic design of connections, like the sizing of washers for a bolted connection in wood, sizing of contact areas for beam and truss supports as well as plate sizes for railroad ties. The loading situations covered in this study are for cases when the partial loading is away from the ends of the members. More studies are necessary to cover situations in which the loading is at the ends of the members.

This study has only addressed the elastic behavior of wood. Future research needs include the need to obtain information on the behavior of wood beyond the elastic limit and strength.

Uhandisi Journal Vol. 15 No. 21991 


\section{LIST OF REFERENCES}

1. American Society for Testing and Materials, 1980, Standard Methods of testing small clear specimens of timber. ASTM Designation D 143-52. Philadelphia, PA

2. Bendtsen, B.A., J.H. Haskell and W.L. Galligan, 1978. Characterizing the stress-compression relationship of wood in compression perpendicular to grain. Wood Science, 10 (3):111121

3. Bodig J.,1969 Improved load carrying capacity of wood in transverse compresion. Forest Prod. J. 19(12):39-44.

4. Bendtsen B.A. and W.L. Galligan, 1979. Modelling the stresscompression relationship in wood in compression perpendicular to grain. Forest Prod. J. 29(2):42-48

5. Bodig J. and B. Jayne, 1982. Mechanics of wood and Wood Composites. Van Nostrand Reinhold Company Inc. New York, NY $712 \mathrm{pp}$.

6. Bodig, J., 1965. The effect of anatomy on the initial stress strain relationship in transverse compression. Forest Prod. J. $15(5): 197-202$.

Uhandisi Journal Vol. 15 No. 21991 
7. Perelvgin, L.M. 1965. Science of Wood. Higher School Publ. House, Moscow 200p.

8. Schniewind, A.P., 1959. Transverse anisotropy of wood Forest Prod. J. 9 (10):350-60.

9. Bodig J. 1966 Stress strain Relationship of wood in transverse compression J. of Materials 1(13):645-666

10. Yamai R., 1955. Stress-strain curves of wood (Report 2) : Stress-strain curves for partial compression perpendicular to grain. Bulletin of the Govt. For Experiment station, Tokyo. No. 78 pp. 101-148.

11. Yamai R. 1959. Studies on the characteristic properties of wood in partial compression. 1. On the distribution of strain in direction of loading J. Japanese Wood Res. Soc. 5(5); 189193.

12. Mrema A.L. 1988. Behaviour of Wood in Transverse Compression. Ph.D dissertation, Colorado State University, U.S.A.

Uhandisi Journal Vol. 15 No. 21991 